\title{
Distribution pattern of the genus Rhododendron in Bhutan Himalayan range
}

\author{
Sangay Namgay ${ }^{\mathrm{a}, \mathrm{b}, *}$, Kitichate Sridith $^{\mathrm{a}}$ \\ a Department of Biology, Faculty of Science, Prince of Songkla University, Songkla 90112 Thailand \\ b Wanakha Central School, Ministry of Education, Royal Government of Bhutan, Thimphu, Bhutan
}

*Corresponding author, e-mail: sangaynamgay@gmail.com

Received 30 Dec 2019

Accepted 23 Jun 2020

\begin{abstract}
The genus Rhododendron is considered one of the relictual plant taxa having circumboreal distribution. However, through vicariance followed by orogeny, the distribution of this plant genus was vastly affected. A total of forty six Rhododendron species in Bhutan Himalayan region share most of its species with central Himalayan countries. Additionally, the genus Rhododendron is found even to the extend to Far East Asia. However, very little information is available on the comparative study of the phytogeographic distributions of genus Rhododendron between Himalayan countries and the extent of East Asia. Various literatures and derived data on the Rhododendron species availability were studied. Findings revealed that the Rhododendron arboreum is found to be widely distributed across the whole Himalayan range to the neighbouring countries in East Asia. It could be reasoned that Rhododendron species of Himalayan range are confined within their geographical boundary and remain isolated from other populations. We proposed that heterogenous environmental condition offered by might have played an important role in sustaining the diversity of Rhododendron in Himalayan range. Although Bhutan Himalayan range is not accounted a center of distribution of Rhododendron species, it might have helped as an important corridor for the dispersal of plant elements as it connects many floristic region and biogeographic realms.
\end{abstract}

KEYWORDS: geographic distribution, Rhododendron, Bhutan Himalayas, phytogeography

\section{INTRODUCTION}

The genus Rhododendron, family Ericaceae is considered an old plant genus which presumably might have occurred ca. 50 million years ago during a tertiary period [1], and it is proposed to be one of the tertiary relict genera where once this plant genus was having circumboreal distribution in the northern hemisphere [2]. Later, during late tertiary period (44-55 million years ago), the collision of Indian plate and Eurasian plate gave rise to the Himalayan mountains (region of extreme relief). With the uplift of the Himalayan mountains and change in climatic condition followed by the geological time scale, the distribution of floristic composition of a plant community was vastly affected [3]. The Himalayan mountain range plays an important role in plant biogeography as it connects different biogeographic realms [4] and provides refuge to many plants due to the unique ecological niche for the diversity of the plants [5]. Moreover, the Himalayan range is important in terms of plant biogeography as the range has connected to many important plant biogeographic regions [6] where Rhododen- dron could be found i.e. Eastern Himalaya province (region 2), Irano-Turanian province (region 8), Sudano-zambazian province (region 12), India (region 16) and Indochinese region (region 17) according to Takhtajan's system of plant geography [7].

Bhutan Himalayas, which forms a major part of eastern Himalayas, is mostly characterized by the geographical complexity and climatic variability $[8,9]$. The vegetation is so diverse that it provides a cradle for vast section of floristic richness, especially Rhododendron where it contributes four percent to the global population of the genus Rhododendron. Bhutan Himalayas harbours fortysix taxa of Rhododendron, mostly belonging to the subgenera Hymenanthes and Rhododendron growing on different geographical mountains forming a critical component of a montane ecosystem.

Tobgye et al [6] studied the comparative study of the floristic elements on the lower montane forest of Bhutan Himalayan range and proposed the probable floristic dispersal routes. Although, Bhutan Himalayas is one of the hosts for the Rhododendrons, the phytogeographic information of this plant genus 
is least achieved. Therefore, the present work tries to draw the patterns of distribution throughout the Himalayan range to East Asia in terms of general phytogeography of Rhododendron.

\section{MATERIALS AND METHODS}

The study was conducted in different geographical ranges from west to east of Bhutan Himalayas covering all the places where a wild population of Rhododendron is found (Fig. 1) i.e. Chele-La $\left(27^{\circ} 37.31^{\prime} \mathrm{N}\right.$; $\left.89^{\circ} 37.27^{\prime} \mathrm{E}\right)$, Dochula $\left(27^{\circ} 48.34^{\prime} \mathrm{N}\right.$; $27^{\circ} 48.34^{\prime}$ E), Pelela $\left(27^{\circ} 51.70^{\prime} \mathrm{N} ; 90^{\circ} 54.89^{\prime} \mathrm{E}\right)$, Yotongla $\left(27^{\circ} 52.14^{\prime} \mathrm{N} ; 90^{\circ} 60.93^{\prime} \mathrm{E}\right)$, Phrumsengla National Park $\left(27^{\circ} 39.84^{\prime} \mathrm{N}\right.$; $\left.90^{\circ} 99.41^{\prime} \mathrm{E}\right)$; Dagala $\left(27^{\circ} 26.58^{\prime} \mathrm{N} ; 89^{\circ} 65.26^{\prime} \mathrm{E}\right)$ and Sakteng $\left(27^{\circ} 41.85^{\prime} \mathrm{N} ; 91^{\circ} 87.62^{\prime} \mathrm{E}\right)$ within an elevation range between $2400-4300 \mathrm{~m}$ above sea level. The vegetation in all geographical regions of the study sites is characterized as a mixed coniferous forest except Sakteng where it is an open wetland valley. Plants were collected from March to July 2019 to cover all the flowering seasons. The distribution of selected Rhododendron species was studied in initial field survey, and a set of parameters including geographic coordinates and habitats was recorded. All the species were photographed and recorded with the field notes. The collected specimens were identified according to the Flora of Bhutan [10]. The herbarium specimens were prepared and deposited in the Bhutan National Herbarium Center, Serbithang.

The information on the distribution of Rhododendron species in Himalayan countries and countries of East Asia where Rhododendron could be found was compiled from available scientific published papers, monographs, online database and published taxonomic books on this plant genus like 'A revision of Rhododendron II. subgenus $\mathrm{Hy}$ menanthes' [11],' The Encyclopedia of Rhododendron Species' [12],' A revision of Rhododendron I. subgenus Hymenanthes. Notes from the Royal Botanic Garden' [13], 'The Rhododendron Species Volume II Elepidotes Species, series ArboreumLacteum' [14], 'Flora of China' [15], 'Rhododendron of China' [16], 'The Rhododendron species in the Indian Eastern Himalaya' [17], 'The Rhododendrons of Nepal' [18] and 'Flora of Thailand' [19]. For the global status of this species, we have referred to 'The red list of Rhododendrons 2011' [20].

\section{RESULTS AND DISCUSSION}

The genus Rhododendron species have wide distribution along Himalayan range of Bhutan (Fig. 2).
Based on the distribution of Rhododendron species from different taxonomic literature, two groups of the taxa could be summarized according to their presence in the given areas. Rhododendron arboreum is found throughout the Himalayas, and it is also found in neighbouring countries from East Asia i.e. Myanmar, Vietnam and Thailand (Table 1) while the other selected taxa are confined to Himalaya region of Bhutan, south-west of China, north-west of India and Nepal Himalayan range.

$R$. arboreum is taxonomically placed under the subgenera Hymenanthes and section Pontica subsection Arborea Sleumer that comprises ca. 300 Rhododendron species [13]. In Bhutan Himalayan range, $R$. arboreum species is widely distributed within the altitudinal range from $2500-3600 \mathrm{~m}$ above sea level, growing on a different ranges of habitats like a rocky cliff, marshland and temperate forest. This taxon occurs as seven different morphological forms, viz., $R$. arboreum var. album Wall, $R$. arboreum subsp. nilagiricum (Zenker) Tagg, $R$. arboreum subsp. arboreum Smith, $R$. arboreum subsp. cinnamomeum (Wallich ex G. Don) Lindley, $R$. arboreum subsp. delavayi (Franchet) Chamberlain, $R$. arboreum subsp. Cinnamomeum var. roseum Lindley and R. arboreum subsp. zeylanicum (Booth) Tagg [13]. Therefore, it could be plausibly reasoned that its high levels of genetic variability and withstanding high and low thermal regime might have attributed to their dominance distribution [21]. However, these paleoendemic taxa hold a subject of much ongoing taxonomic debate especially regarding the center of diversity and a gradual migration of Rhododendron taxa [20].

Another plausible explanation for the wide distribution of $R$. arboreum could be related to ecological niche theory [22]. $R$. arboreum species is the only species that holds a wide range of altitudinal distribution (Table 2) and habitats. Chandra et al [23] also spotted $R$. arboreum below $1000 \mathrm{~m}$ in Indian Himalayan region. Kuttapety et al [24] reported that annual mean temperature was found to be an ecological factor that defined the survival of $R$. arboreum var. cinnamomeum and $R$. arboreum var. arboreum in a different geographical locations of Indian Himalayan range. $R$. arboreum has high degree of adaptability and grows in a different habitat. Due to its broad realized niche and high recolonization ability, it competes with other plants and grows with already established vegetation [21]. Further, some species like $R$. arboerum subsp. Nilagiricum is found in the south Western Ghats of India and even in the moun- 


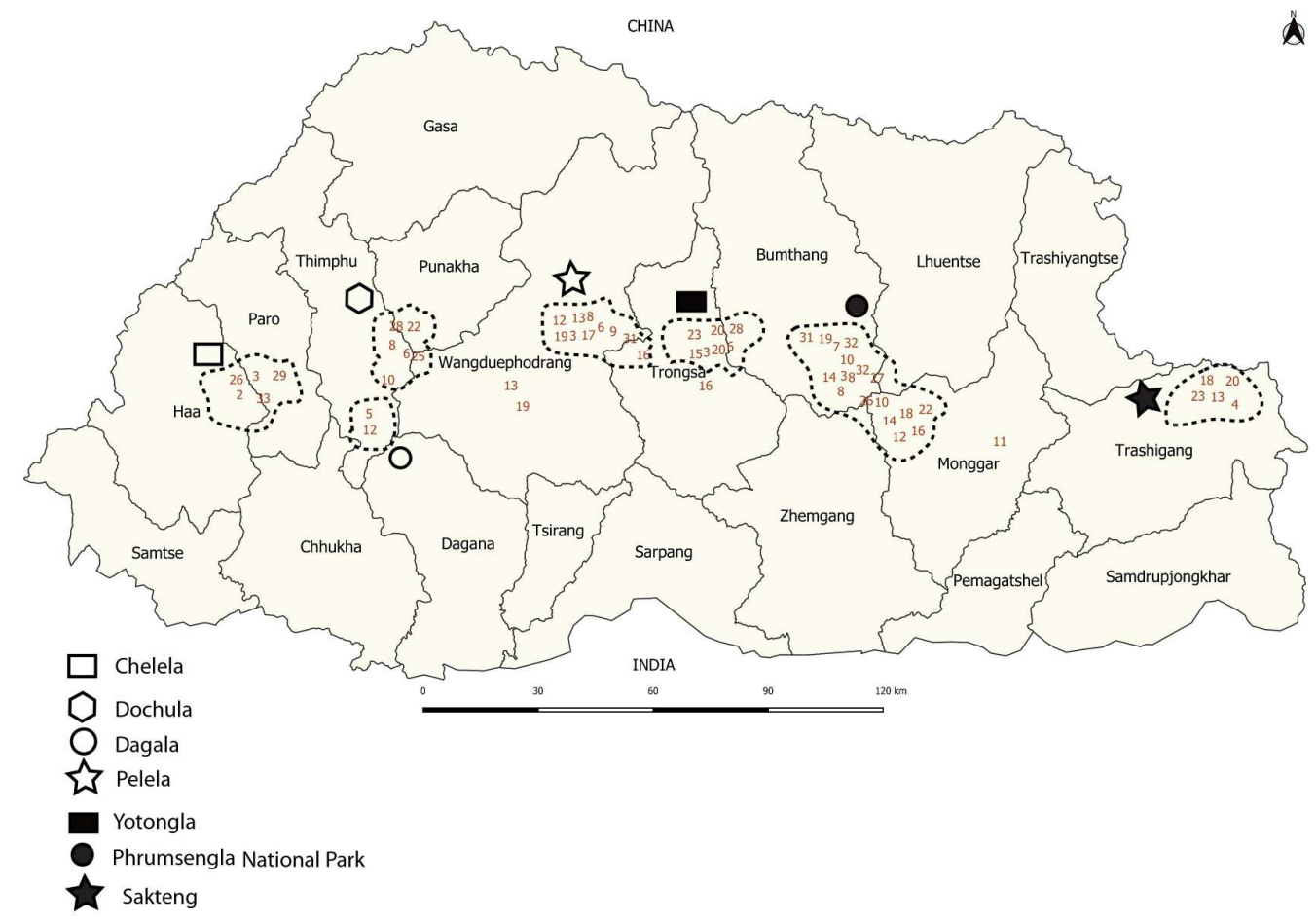

Fig. 1 Map showing the distribution of genus Rhododendron on different geographical mountain ranges of Bhutan Himalayas. Rhododendron species: 1, R. aeruginosum Hook. f.; 2, R. anthopogon Wall; 3, R. arboreum Smith; 4, R. argipeplum Balfour \& Cooper; 5, R. baileyi Balfour \& Cooper; 6, R. barbatum G. Don; 7, R. campanulatum D. Don; 8, R. campylocarpum Hook. f.; 9, $R$. Ciliatum Hook. f.; 10, $R$. cinnabarinum Hook. f.; 11, $R$. dalhousiae var. rhabdotum Balfour \& Cooper; 12, R. edgeworthii Hook. f.; 13, R. falconeri Hook. f.; 14, R. fulgens Hook. f.; 15, R. grande Wight; 16, R. graffithianum Wight; 17, R. hodgsonii Hook. f.; 18, R. Kendrickii Nuttall; 19, R. kesangiae Long \& Rushforth; 20, R. keysii Nuttall; 21, R. lanatum Hook. f.; 22, R. lindleyi Moore; 23, R. maddenii Hook. f.; 24, R. neriiflorum Franchet; 25, R. niveum Hook. f.; 26, R. setosum D. Don; 27 R. succothii Davidian; 28, R. thomsonii Hook. f.; 29, R. triflorum Hook. f.; 30, R. tsariense Cowan; 31, R. virgatum Hook. f.; 32, R. wallichii Hook. f. and 33, R. wightii Hook. f.

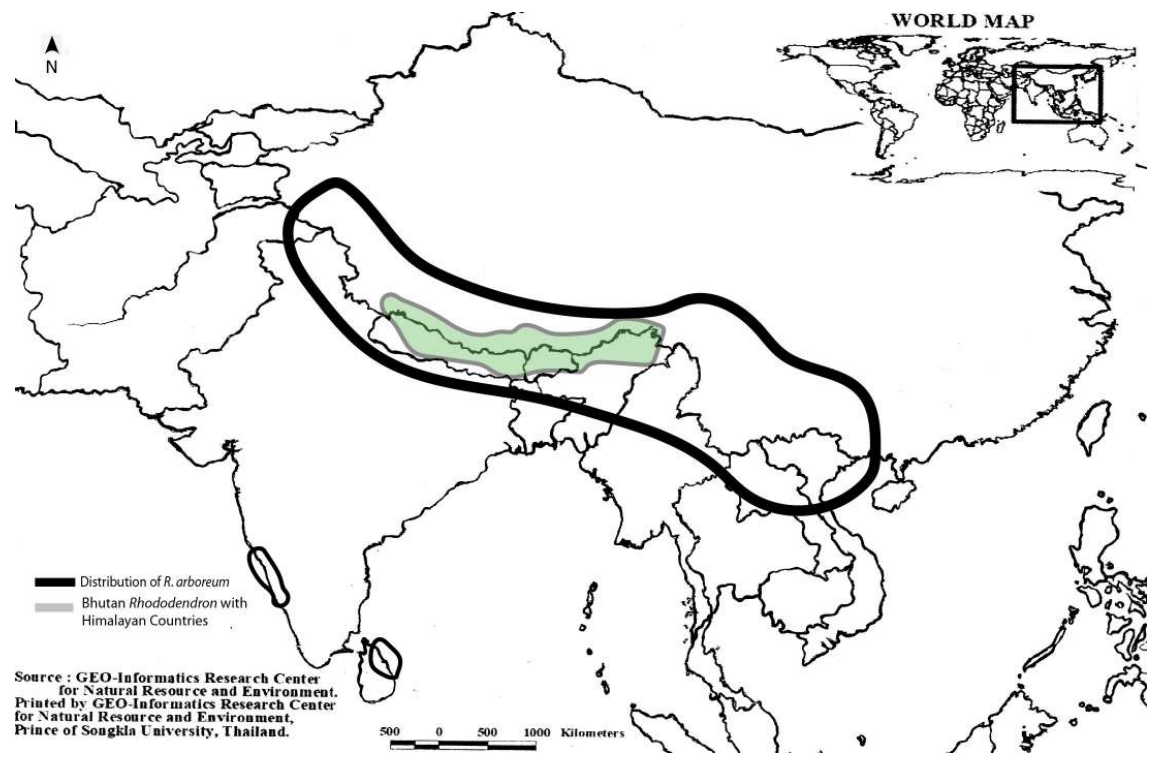

Fig. 2 Map showing the distribution of Rhododendron species in the Himalayan range and East Asia. 
Table 1 List of Rhododendron species in Bhutan Himalayas in comparison with their occurrence in Himalayan and East Asian countries.

\begin{tabular}{|c|c|c|c|c|c|c|c|c|c|c|}
\hline Rhododendron species & Bhu & Chi & Ind & Nep & Pak & Mym & Viet & Thai & Habit & Status \\
\hline R. aeruginosum Hook. $\mathrm{f}$. & $x$ & $x$ & & & & & & & 1 & 2 \\
\hline R. anthopogon D. Don & $x$ & $x$ & $x$ & $\times$ & & $x$ & & & 2 & 2 \\
\hline R. arboreum Smith & $x$ & $\times$ & $\times$ & $\times$ & $\times$ & $\times$ & $\times$ & $\times$ & 3 & 2 \\
\hline R. argipeplum Balfour \& Copper & $x$ & $x$ & $x$ & $\times$ & & & & & 4 & 2 \\
\hline R. baileyi Balfour f. & $x$ & $x$ & $x$ & & & & & & 4 & 2 \\
\hline R. barbatum G. Don & $x$ & $x$ & $x$ & $x$ & & & & & 4 & 1 \\
\hline R. bhutanense Long \& Bowes Lyon* & $x$ & & & & & & & & 4 & 1 \\
\hline R. camelliiflorum Hook. $\mathrm{f}$. & $x$ & $x$ & $\times$ & $x$ & & & & & 4 & 2 \\
\hline R. campanulatum D.Don & $x$ & $x$ & $\times$ & $\times$ & & & & & 4 & 2 \\
\hline R. campylocarpum Hook. f. & $x$ & $x$ & $x$ & $\times$ & & & & & 4 & 2 \\
\hline R. ciliatum Hook. f. & $x$ & $\times$ & $\times$ & $x$ & & $\times$ & & & 4 & 2 \\
\hline R. cinnabarinum Hook. $\mathrm{f}$. & $\times$ & $\times$ & $x$ & $\times$ & & & & & 4 & 2 \\
\hline R. dalhousiae var. rhabdotum Balfour \& Cooper & $x$ & $x$ & $\times$ & & & $\times$ & & & 4 & 2 \\
\hline R. edgeworthii Hook. f. & $x$ & $x$ & $x$ & & & $x$ & & & 4 & 2 \\
\hline R. falconeri Hook. f. & $x$ & & $\times$ & & & & & & 3 & 2 \\
\hline R. fragariiflorum Kingdon Ward & $x$ & $x$ & & $x$ & & & & & 4 & 2 \\
\hline R. flinckii Davidian & $x$ & & & $x$ & & & & & 4 & 1 \\
\hline R. fulgens Hook. f.* & $x$ & $x$ & $\times$ & & & $\times$ & & & 4 & 2 \\
\hline R. glaucophyllum Rehder & $x$ & $x$ & $\times$ & $x$ & & & & & 4 & 2 \\
\hline R. grande Wight & $x$ & $\times$ & $\times$ & $x$ & & & & & 3 & 2 \\
\hline R. griffithianum Wight & $x$ & $x$ & $\times$ & $x$ & & & & & 3 & 2 \\
\hline R. hodgsonii Hook. f. & $x$ & $x$ & $x$ & $x$ & & $x$ & & & 3 & 2 \\
\hline R. kendrickii Nuttall & $x$ & $x$ & & $x$ & & & & & 4 & 2 \\
\hline R. kesangiae Long \& Rushforth & $x$ & & & & & & & & 3 & 2 \\
\hline R. keysii Nuttall* & $x$ & $x$ & $x$ & & & & & & 4 & 2 \\
\hline R. lanatum Hook. f. & $x$ & $x$ & $x$ & & & & & & 4 & 1 \\
\hline R. lepidotum G. Don & $x$ & $x$ & $x$ & & & $x$ & & & 4 & 2 \\
\hline R. leptocarpum Nuttall & $x$ & $x$ & $x$ & $x$ & & $x$ & & & 4 & 2 \\
\hline R. lindleyi Moore & $x$ & $x$ & $x$ & & & $x$ & & & 4 & 2 \\
\hline R. maddenii Hook. f. & $x$ & $x$ & $x$ & $x$ & & $x$ & & & 3 & 2 \\
\hline R. neriiflorum Franchet & $x$ & $x$ & & $x$ & & $x$ & $x$ & $x$ & 4 & 2 \\
\hline R. nivale Hook. f. & $x$ & $x$ & $x$ & & & & & & 4 & 2 \\
\hline R. niveum Hook. f. & $x$ & $x$ & $\times$ & $x$ & & & & & 3 & 1 \\
\hline R. papillatum Hook. f. & $x$ & $x$ & $x$ & & & & & & 4 & 1 \\
\hline R. pendulum Hook. f. & $x$ & $\times$ & $x$ & $x$ & & & & & 2 & 2 \\
\hline R. pogonophyllum Cowan & $x$ & & & & & & & & 4 & 1 \\
\hline R. pumilum Hook. f.* & $\times$ & $x$ & $x$ & $\times$ & & $\times$ & & & 4 & 2 \\
\hline R. setosum D. Don & $x$ & $x$ & $x$ & $\times$ & & & & & 2 & 2 \\
\hline R. succothii Davidian & $x$ & & $x$ & & & & & & 4 & 2 \\
\hline R. thomsonii Hook. f. & $x$ & $x$ & $x$ & $x$ & & & & & 4 & 2 \\
\hline R. triflorum Hook. f. & $x$ & $x$ & $x$ & $x$ & & $x$ & & & 4 & 2 \\
\hline R. tsariense Cowan & $\hat{x}$ & $x$ & & $\hat{x}$ & & & & & 4 & 1 \\
\hline R. vacciniodes Hook. f. & $x$ & $x$ & $x$ & $x$ & & $x$ & & & 4 & 2 \\
\hline R. virgatum Hook. f. & $x$ & $x$ & $x$ & $x$ & & & & & 4 & 2 \\
\hline R. wallichii Hook. f. & $\times$ & $x$ & $\times$ & $\times$ & & & & & 4 & 2 \\
\hline R. wightii Hook. f. & $\times$ & $x$ & $x$ & $x$ & & & & & 4 & 2 \\
\hline
\end{tabular}

"Endemic to Bhutan. Countries: Bhu, Bhutan; Chi, China; Ind, India; Nep, Nepal; Pak, Pakistan; Mym, Myanmar; Viet, Vietnam and Thai, Thailand. Habit: 1, krummholz; 2, prostrate shrub; 3, tree and 4, shrubby tree. Status: 1, globally threatened Rhododendron; 2, least concern.

tain forest of Sri Lanka [21]. Therefore, these taxa stimulate an intriguing questions about the course of evolution.

When floral morphology of $R$. arboreum is taken into account, it is assumed that this species could be pollinated both by bees and birds which might have helped in rapid seed developmental allometries due to high visitation rate by the different pollinators [25]. The $R$. arboreum tree which extended up to $15-20 \mathrm{~m}$ in height coupled with superior capacity to disperse by wind and animals owing to small and light seeds [26] might have triggered long dispersal and adaptation. Through dispersal means, it might have therefore used as an evolutionary measure for a wide distribution of such plant taxa, especially $R$. arboreum where it has a diverse distribution over the Himalayan range to East Asia. However, further in-depth study of the phytogeography, molecular phylogenetic analysis as well as the pollination ecology and seed dispersal of this plant taxa is suggested to encourage future research on a topic that deserves further consideration.

Bhutan Himalayan kingdom retains four endemic Rhododendron species out of forty-six [10] i.e. $R$. bhutanense Long \& Bowes Lyon, R. flinckii Davidian, R. kesangiae Long \& Rushforth and 
Table 2 Environmental variables and Rhododendron species that are grown in different study sites in Bhutan Himalayan range.

\begin{tabular}{|c|c|c|c|c|c|}
\hline Species & Altitude (m) & Flowering & Habitat $^{\dagger}$ & Height (m) & Site $^{\dagger}$ \\
\hline R. aeruginosum Hook. f. & $3700-4000$ & May-Jun & 1 & $2 \pm 1$ & 2 \\
\hline R. anthopogon D. Don & $3900-4200$ & Jun-Jul & 1 & $0 . \overline{3} \pm 0.2$ & 124 \\
\hline R. arboreum Smith & $2500-3600$ & Mar-Apr & 123 & $20 \pm 5$ & 123456 \\
\hline R. argipeplum Balfour \& Copper & $2700-3400$ & Apr-May & 2 & $3 \pm 2$ & 45 \\
\hline R. baileyi Balfour $\mathrm{f}$. & $3000-4000$ & May-Jul & 1 & $1.5 \pm 0.5$ & 2 \\
\hline R. barbatum G. Don & $3000-3600$ & Mar-Apr & 2 & $6 \pm 2$ & 134 \\
\hline R. campanulatum D.Don & $3100-3700$ & May-Jun & 2 & $4.0 \pm 1.5$ & 6 \\
\hline R. campylocarpum Hook. f. & $3000-3600$ & Apr-May & 2 & $6 \pm 2$ & 146 \\
\hline R. ciliatum Hook. f. & $2700-3200$ & Apr-Jun & 4 & $1.5 \pm 1.0$ & 4 \\
\hline R. cinnabarinum Hook. $\mathrm{f}$. & $3100-3700$ & May-Jul & 2 & $6 \pm 2$ & 146 \\
\hline R. dalhousiae var. rhabdotum Balfour \& Cooper & $2100-2600$ & May-Jun & 3 & $7 \pm 3$ & 6 \\
\hline R. edgeworthii Hook. f. & $2500-3000$ & Apr-May & 3 & $5 \pm 2$ & 346 \\
\hline R. falconeri Hook. f. & $2500-3100$ & Apr-May & 2 & $20 \pm 7$ & 3456 \\
\hline R. fulgens Hook. f. & $2900-3500$ & May-Jun & 2 & $5 \pm 2$ & 6 \\
\hline$R$. grande Wight & $2100-2900$ & Feb-Mar & 2 & $10 \pm 5$ & 456 \\
\hline R. griffithianum Wight & $2000-2600$ & Mar-May & 2 & $7 \pm 4$ & 34 \\
\hline R. hodgsonii Hook. f. & $3000-3600$ & Apr-May & 2 & $15 \pm 5$ & 146 \\
\hline R. kendrickii Nuttall & $2400-3200$ & Mar-Apr & 2 & $6 \pm 2$ & 6 \\
\hline R. kesangiae Long \& Rushforth & $2600-3400$ & Apr-May & 2 & $25 \pm 6$ & 3456 \\
\hline R. keysii Nuttall & $2600-3500$ & May-Jul & 2 & $3.0 \pm 1.5$ & 346 \\
\hline R. lanatumHook. f. & $3500-3900$ & May-Jun & 2 & $4 \pm 1$ & 6 \\
\hline R. lindleyi Moore & $2000-2800$ & Apr-May & 3 & $5 \pm 2$ & 6 \\
\hline R. maddenii Hook. f. & $2100-2900$ & Apr-Jun & 3 & $3.5 \pm 1.0$ & 5 \\
\hline R. neriiflorum Franchet & $2500-3100$ & Mar-May & 2 & $4 \pm 2$ & 4 \\
\hline R. niveum Hook. f. & $2900-3700$ & Apr-May & 2 & $8 \pm 5$ & 3 \\
\hline R. setosum D. Don & $3000-4000$ & Jun-Aug & 1 & $0.3 \pm 0.2$ & 12 \\
\hline R. succothii Davidian & $3100-3900$ & Apr-May & 2 & $3 \pm 2$ & 6 \\
\hline R. thomsonii Hook. f. & $2900-3600$ & May-Jun & 4 & $6 \pm 3$ & 356 \\
\hline R. triflorum Hook. f. & $2300-3600$ & Apr-Jun & 2 & $4 \pm 2$ & 134 \\
\hline R. tsariense Cowan & $3300-3900$ & May-Jun & 2 & $5 \pm 2$ & 6 \\
\hline R. virgatum Hook. f. & $2400-2700$ & Apr-May & 2 & $3 \pm 1$ & 6 \\
\hline R. wallichii Hook. f. & $2800-3900$ & Apr-Jun & 2 & $6 \pm 1$ & 16 \\
\hline R. wightii Hook. f. & $3600-4300$ & May-Jun & 2 & $6 \pm 2$ & 16 \\
\hline
\end{tabular}

${ }^{\dagger}$ Habitats: 1, alpine shrub; 2, forest; 3, rocky cliff; 4, marsh land.

Sites: 1, Chelela; 2, Dagala; 3, Dochula; 4, Pelela; 5, Sakteng; 6, Phrumsengla National park.

Table 3 Total number of Rhododendron species and number of endemic species in different countries.

\begin{tabular}{lccccccc}
\hline Country & Bhutan & China & India & Nepal & Myanmar & Thailand & Vietnam \\
\hline Total Number of Rhododendron species & 46 & 571 & 87 & 30 & 205 & 12 & 90 \\
Number of endemic species & 4 & 423 & 20 & 1 & $*$ & 0 & 12 \\
\hline
\end{tabular}

" Not assessed.

R. pogonophyllum Cowan (Table 1). Although Grierson et al [10] have proposed the Rhododendron species of Bhutan, the enumeration study was confined only in the western and the central part of Bhutan. The extensive survey might have been limited due to rigid and rugged mountain terrains where it remains inaccessible. There are chances that many more species or new record of Rhododendron species from other geographical locations of Bhutan could be later found since Bhutan Himalayan region seems likely to offer the refuge of Rhododendron species owing to the country's geographic complexities fueled by varying environmental clines.

Bhutan Himalayas shares most of the Rhododendron species with Nepal, India and Southwest China
Himalayan range e.g. R. anthopogon (Fig. 3B), $R$. arboreum (Fig. 3C), R. argipeplum (Fig. 3D), R. barbatum (Fig. 3F), R. campylocarpum (Fig. 3G), $R$. ciliatum (Fig. $3 \mathrm{H}$ ), R. cinnabarinum (Fig. 3I), R. grande (Fig. $3 \mathrm{M}$ ), R. griffithianum (Fig. $3 \mathrm{~N}$ ), R. hodgsonii (Fig. 3O), R. maddenii (Fig. 4E), R. niveum (Fig. 4G), R.setosum (Fig. 4H), R. thomsonii (Fig. 4J), R. triflorum (Fig. 4K), R. virgatum (Fig. 4M), R. wallichii (Fig. 4N) and $R$. wightii (Fig. 4O). It could be hypothesized that the formation of Himalayan mountain range particularly Bhutan, Nepal, south west of China and north east of India by the collision between Indian Plate and Eurasian Plate which began ca. 50 million years ago [1] might have created a heterogeneous topography. This topographic complexity may have 

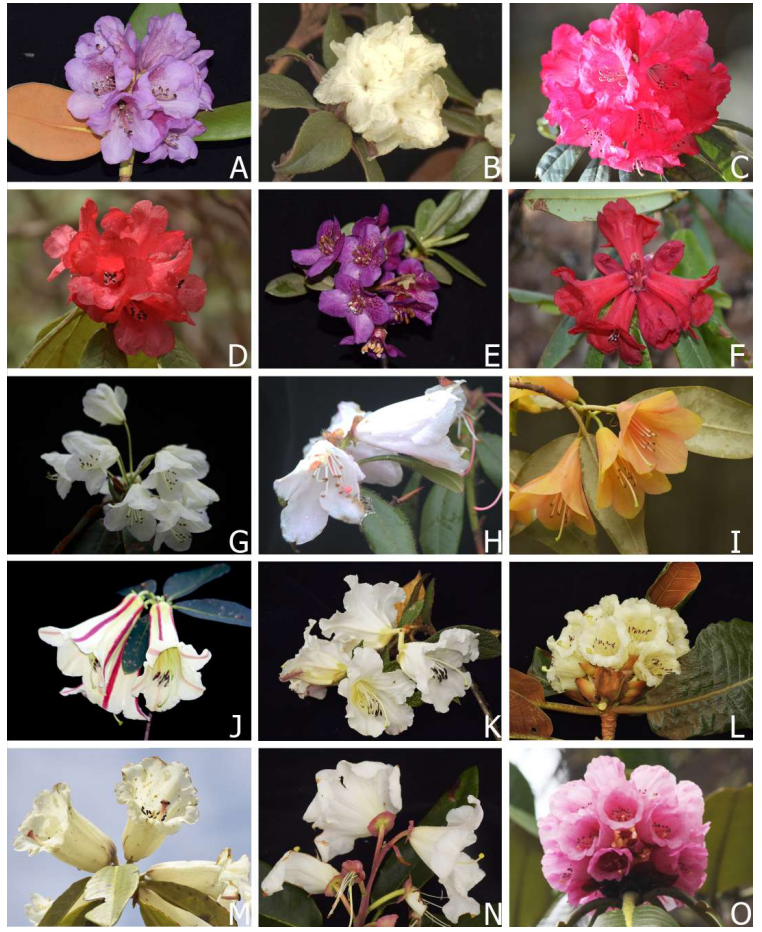

Fig. 3 Flowers of: A, R. aeruginosum; B, R. anthopogon; C, $R$. arboreum; D, R. argipeplum; E, R. baileyi; F, R. barbatum; G, R. campylocarpum; H, R. ciliatum; I, R. cinnabarinum; J, R. dalhousiae var. rhabdotum; K, R. edgeworthii; $\mathrm{L}, R$. falconeri; $\mathrm{M}, R$. grande; $\mathrm{N}, R$. griffithianum and $\mathrm{O}, \mathrm{R}$. hodgsonii.

helped to create the array of climatic niches and to increase the opportunities for the geographical barrier which gradually accentuates in forming a reproductive isolation where species diversity occurs [27]. Similarly, with the development of complex topography, it might have promoted in forming a unique environmental niche. Thus, the geographic reproductive isolation fueled by the heterogeneous habitat might have promoted the diversification of Rhododendron species through allopatric speciation and adaptation to the varying environmental clines [27]. Therefore, the countries of East Asia might not share a common Rhododendron species with the Himalayan countries due to its varying nature of habitats and environmental conditions.

Through the study of endemic species of Rhododendron in different countries (Table 3), it is supposed that Bhutan Himalayan region might not be a center of diversity of Rhododendron species due to its minimum genetic diversity as proposed by Ranjitkar et al [21]. However, it could be suggested that it might have acted as an important corridor for
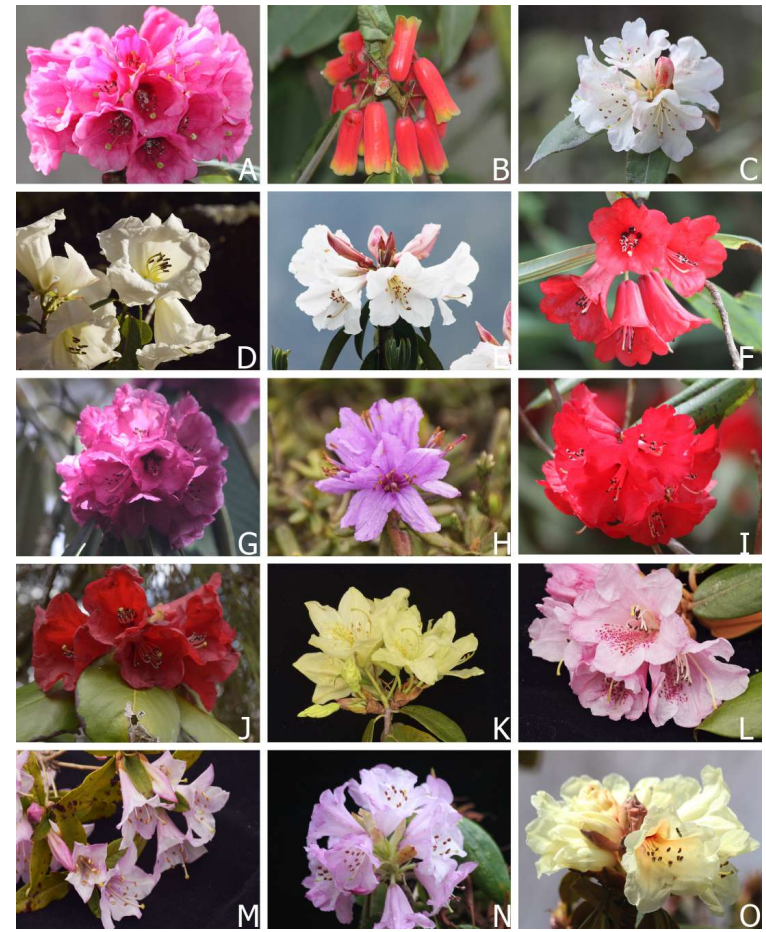

Fig. 4 Flowers of: A, R. kesangiae; B, R. keysii; C, R. lanatum; D, R. lindleyi; E, R. maddenii; F, $R$. neriiflorum; $\mathrm{G}, R$. niveum; H, R. setosum; I, R. succothii; J, R. thomsonii; $\mathrm{K}, R$. triflorum; L, R. tsariense; $\mathrm{M}, R$. virgatum; N, R. wallichii and $\mathrm{O}, \mathrm{R}$. wightii.

the distribution for many plant elements of different plant genera, especially the plant genus Rhododendron.

Acknowledgements: This research has been supported by Centre of Excellence on Biodiversity (BDC), Office of Higher Education Commission (BDC-PG3-160016), Ministry of Higher Education, Science Research and Innovation, Thailand. We would like to extend our sincere and humble credit to the Graduate School of Prince of Songkla University and Thailand's Education Hub for ASEAN Countries for the scholarship. We would like to thank Mr. Tenzinla and Mr. Rinchen Dorji from National Biodiversity Centre, Serbithang, Thimphu for the assistance during data collections in the field and finally to thank Mr. Jigme Tshewang, Mr. Dorji Wangchuk and Mr. Anusit Cheechang for the assistance.

\section{REFERENCES}

1. Irving E, Hebda R (1993) Concerning the origin and distribution of Rhododendrons. J Amer Rhododendron Soc 47, ID 139.

2. Chamberlain DF, Hyam R, Argent G, Fairweather G, Walters KS (1996) The Genus Rhododendron: Its Clas- 
sification and Synonymy, Royal Botanical Garden, Edinburg.

3. Milne RI (2006) Northern hemisphere plant disjunctions: a window on tertiary land bridges and climate change? Ann Bot 98, 465-472.

4. Jamtsho K, Sridith K (2015) Exploring the patterns of alpine vegetation of eastern Bhutan: A case study from the Merak Himalaya. Springplus 4, ID 304.

5. Chaudhary S, Tshering D, Phuntsho T, Uddin K, Shakya B, Chettri N (2017) Impact of land cover change on a mountain ecosystem and its services: Case study from Phobjikha valley, Bhutan. Ecosyst Health Sustain 3, ID 1393314.

6. Tobgye T, Sridith K (2018) Preliminary notes on distribution of Himalayan plants elements: A case study from Eastern Bhutan. Songklanakarin $J$ Sci Technol 40, 370-378.

7. Takhtajan A (1986) Floristic Region of the World, University of California Press, Berkeley, CA.

8. Oshawa M (1987) Life Zone Ecology of the Bhutan Himalaya, Chiba University, Japan.

9. National Biodiversity Centre (2009) Biodiversity Action Plan, MoAF, Royal Government of Bhutan.

10. Grierson AJC, Long DG (1991) Flora of Bhutan, vol 2(I), Royal Botanical Garden, Edinburg.

11. Chamberlain DF (1982) A Revision of Rhododendron II. subgenus Hymenanthes. Note Roy Bot Gard Edinburgh 39, mbox209-486.

12. Cox PA, Cox KNE (1997) The Encyclopedia of Rhododendron Species, Glendoick Publishing, Perth, Scotland.

13. Cullen J (1980) A revision of Rhododendron I. subgenus Hymenanthes. Note Roy Bot Gard Edinburgh 39 , 1-207.

14. Davidian HH (1989) The Rhododendron Species Volume II Elepidotes Species, Series Arboreum-Lacteum, Timber Press Inc, Batsford, London.

15. Fang MY, Fang RC, He MY, Hu LZ, Yang HB, Chamberlain DF (2005) Ericaceae. In: Wu ZY, Raven PH, Hong DY (eds) Flora of China, Vol. 14, Science Press, Beijing, pp 260-455.

16. Feng G (1988) Rhododendrons of China, Vol. I, Science Press, Beijing.

17. Menon S, Latif Khan M, Paul A, Peterson AT (2012)
Rhododendron species in the Indian Eastern Himalaya: New approaches to understanding rare plant species distribution. $J$ Amer Rhododendron Soc $66,78-84$.

18. De Milleville R (2002) The Rhododendrons of Nepal, Himal Books, Katmandu, Nepal.

19. Santisuk T, Balslev H, Newman M, Barfod A (2015) Flora of Thailand, Vol. 13(I), The Forest Herbarium, Department of National Parks, Wildlife \& Plant Conservation, Bangkok.

20. Gibbs D, Chamberlain D, Argent G (2011) The Red List of Rhododendrons, Botanic Gardens Conservation International, Richmond, UK.

21. Ranjitkar S, Kindt R, Sujakhu NM, Hart R, Guo W, Yang X, Shrestha KK, Xu J, et al (2014) Separation of the bioclimatic spaces of Himalayan tree Rhododendron species predicted by ensemble suitability models. Glob Ecol Conserv 1, 2-12.

22. Vetaas OR (2002) Realized and potential climate niches: A comparison of four Rhododendron tree species. J Biogeogr 29, 545-554.

23. Sekar KC, Srivastava KS (2010) Rhododendrons in Indian Himalayan region: Diversity and Conservation. Am J Plant Sci 1, 131-137.

24. Kuttapetty M, Pillai PP, Varghese JR, Seeni S (2014) Genetic diversity analysis in disjunct populations of Rhododendron arboreum from the temperate and tropical forests of Indian subcontinent corroborate satpura hypothesis of species migration. Biologia 69 , 311-322.

25. Howell V, Jesson LK (2013) The effect of bird and bee visitation on pollination and reproductive success in Phormium tenax. N Z J Bot 51, 194-205.

26. Wang Y, Wang J, Lai L, Jiang L, Zhuang L, Zhang L, Zheng Y, Baskin JM, et al (2014) Geographic variation in seed traits within and among forty-two species of Rhododendron (Ericaceae) on the Tibetan plateau: Relationships with altitude, habitat, plant height, and phylogeny. Ecol Evol 4, 1913-1923.

27. Shrestha N, Wang Z, Su X, Xu X, Lyu L, Liu Y, Drimitrov D, Kennedy JD, et al (2018) Global patterns of Rhododendron diversity: The role of evolutionary time and diversification rates. Global Ecol Biogeogr 27, 913-924. 